\title{
Authentication analysis of milkfish fish oil using the combination of FTIR spectroscopy and chemometrics
}

\author{
${ }^{1}$ Mustafidah, M., ${ }^{2}$ Irnawati, I., ${ }^{1}$ Lukitaningsih, E. and ${ }^{1,3}$ Rohman, A. \\ ${ }^{I}$ Department of Pharmaceutical Chemistry, Faculty of Pharmacy, Gadjah Mada University, Yogyakarta, \\ 55281 Indonesia \\ ${ }^{2}$ Faculty of Pharmacy, Halu Oleo University, Kendari, 93232, Indonesia \\ ${ }^{3}$ Center of Excellence, Institute for Halal Industry and System (IHIS), Gadjah Mada University, Yogyakarta, \\ 55281, Indonesia
}

\begin{abstract}
Article history:
Received: 24 October 2020

Received in revised form: 25

November 2020

Accepted: 11 December 2020

Available Online: 28 March

2021
\end{abstract}

Keywords:

Milkfish oil,

Multivariate calibration,

FTIR spectroscopy,

Authentication analysis,

Discriminant analysis

DOI:

https://doi.org/10.26656/fr.2017.5(2).607

\begin{abstract}
Milkfish (Chanos chanos) is one of the highest-produced fish in Indonesia. Milkfish fish oil (MFO), extracted from milkfish, contains essential fatty acids and has a high price in the market, therefore MFO can be a target of adulteration. The objective of this study was to perform an authentication analysis of MFO from palm oil using FTIR spectroscopy and chemometrics. MFO was extracted from the head and flesh of milkfish and the obtained MFO was mixed with palm oil (PO) in binary mixtures to get the adulteration model of MFO with PO. All samples were scanned using ATR-FTIR at wavenumbers of 4000-650 $\mathrm{cm}^{-1}$. Classification between authentic MFO and adulterated MFO with PO was carried out using discriminant analysis. The quantitative analysis of MFO adulterated with PO was carried out with PLSR (Partial Least Square regression) using first derivative spectra with wavenumbers of $3100-670 \mathrm{~cm}^{-1}$. The $\mathrm{R}^{2}$ values for the correlation between the actual and predicted values in the calibration and validation of MFO were 0.9999 and 0.9994 (MFO extracted from the head) and 0.9997 and 0.9992 (MFO extracted from flesh), respectively. In addition, RMSE (root mean square errors) values of the calibration and prediction of milkfish head oil were $0.0032 \%$ and $0.0106 \%$, while MFO extracted from the flesh was $0.0080 \%$ and $0.0123 \%$. It can be concluded that FTIR spectroscopy combined with PLSR could be reliable for the prediction of MFO in a binary mixture with palm oil.
\end{abstract}

\section{Introduction}

Milkfish is consumed in Indonesia, Philippines, Taiwan, Malaysia, Thailand, and other countries. In Indonesia, milkfish is known as "Ikan Bandeng". Milkfish is considered a "fatty" fish because it has more fat in its body (Bayaga and Devega, 2005). The nutritional composition of freshly cultured milkfish revealed that the fish had a good quantity of protein, amino acids and poly-unsaturated fatty acids. Fresh milkfish is rich in unsaturated fatty acids $(50.74 \%)$ of which monounsaturated fatty acids (MUFA) and polyunsaturated fatty acids (PUFA) constituted 34.47 and $16.27 \%$, respectively (Murthy et al., 2016). Fish oil is the main source of lipid with an essential omega-3 unsaturated fatty acid, predominantly eicosapentaenoic acid (EPA) and docosahexaenoic acid (DHA) (Ali, 2017). Consumption of omega-3 fatty acid can prevent many diseases especially cardiovascular disorders by reducing risk factors such as heart arrhythmias, blood pressure, triglyceride concentrations and platelet aggregation (Durmuş, 2019). The USDA (United State Departments of Agriculture) reported that Salmo salar (S. salar), especially the Atlantic salmon, contain high levels of EPA and DHA. Unfortunately, salmon is known to be expensive due to their susceptibility to sea lice and changes in ocean condition (Sugata et al., 2019). Therefore, milkfish is a potential candidate species with good production potential to be used as a source of fish oil.

Fish oil extracted from milkfish might have the same composition as other fish oils, as a consequence milkfish oil (MFO) is could be adulterated with lower-priced oils such as palm oil and corn oil (Christy et al., 2004). Unethical producers may adulterate MFO with the PO to get economical gains, but this practice could decrease the quality of MFO (Rohman et al., 2019). Among the 
physico-chemical methods, FTIR spectroscopy combined with partial least square (PLS) regression and principal component regression (PCR) is the most common method applied for the prediction of adulteration level of fish oil due to its nature as a fingerprint analytical technique (Rohman, 2017). The precision and accuracy of the PLS and the PCR model were based on the root mean squared error of calibration (RMSEC), root mean squared error of prediction (RMSEP) and coefficient of determination $\left(\mathrm{R}^{2}\right)$ values (Gezahegn, 2018).

FTIR spectroscopy in combination with chemometrics has been used for authentication of virgin coconut oil from grape seed oil and soybean oil (Rohman, Che Man and Ali, 2019), corn and soybean oils in red fruit oil (Setyaningrum et al., 2013), authentication of Patin fish oil (Putri et al., 2019), authentication of cod liver oil (Rohman et al., 2017) and authentication of pumpkin seed oil from sesame oil (Irnawati et al., 2019b). However, there is no publication reporting the application of FTIR spectroscopy coupled with chemometrics for authentication of MFO. The goal of this research was to perform authentication of MFO from palm oil (PO) using FTIR spectroscopy combined with chemometrics. Palm oil was selected as an oil adulterant from vegetable oil and fish oils as an adulterant because have a similar physical form and an affordable price.

\section{Materials and methods}

\subsection{Materials}

Milkfish was obtained from a local fish market in Juwana Pati, Central Java, Indonesia. The vegetable oils and fish oils namely palm oil, olive oil, fat pork, candlenut oil, red fruit oil, bulus oil, shark oil, patin fish oil, soybean oil, sunflower oil, cod liver oil, tunghai fish oil, salmon fish oil, grape seed oil, corn oil, and Habbatus sauda oil. used during principal component analysis were purchased from local market around Yogyakarta, Indonesia.

\subsection{Extraction of milkfish oil}

Milkfish oil (MFO) was extracted from the head and flesh of milkfish by placing both in an aluminium tray and were dried using a cabinet dryer in $50^{\circ} \mathrm{C}$ for about 24 hrs. MFO was extracted using direct pressing with 100 $\mathrm{kN}$ force for 2 mins. The samples were then centrifugated using $5000 \times g$ for 10 mins to separate sediment.

\subsection{Preparation of binary mixtures milkfish and palm oil}

Milkfish oil and palm oil were mixed in binary mixture with concentration ranges $0-100 \% \mathrm{v} / \mathrm{v}$ of oils (Table 1). The samples used a different range of concentration to determine if the concentration range had an effect on the authentication results. All samples were analysed using FTIR spectroscopy. The prediction of adulterant level was carried out using multivariate calibrations, while pure MFO and MFO adulterated with PO were classified and discriminated against using Discriminant Analysis based on their FTIR spectra at certain wavenumbers.

Table 1. The calibration samples containing of Flesh milkfish fish oil and palm oil [A], and Head milkfish fish oil and palm oil [B]

\begin{tabular}{|c|c|c|c|}
\hline \multirow[t]{26}{*}[\mathrm{A}]{} & Sample & Flesh milkfish oil (\%) & Palm oil (\%) \\
\hline & 1 & 100 & 0 \\
\hline & 2 & 97 & 3 \\
\hline & 3 & 95 & 5 \\
\hline & 4 & 90 & 10 \\
\hline & 5 & 85 & 15 \\
\hline & 6 & 80 & 20 \\
\hline & 7 & 75 & 25 \\
\hline & 8 & 70 & 30 \\
\hline & 9 & 65 & 35 \\
\hline & 10 & 60 & 40 \\
\hline & 11 & 57 & 43 \\
\hline & 12 & 55 & 45 \\
\hline & 13 & 50 & 50 \\
\hline & 14 & 45 & 55 \\
\hline & 15 & 43 & 57 \\
\hline & 16 & 40 & 60 \\
\hline & 17 & 35 & 65 \\
\hline & 18 & 30 & 70 \\
\hline & 19 & 25 & 75 \\
\hline & 20 & 20 & 80 \\
\hline & 21 & 15 & 85 \\
\hline & 22 & 10 & 90 \\
\hline & 23 & 5 & 95 \\
\hline & 24 & 3 & 97 \\
\hline & 25 & 0 & 100 \\
\hline \multirow[t]{21}{*}{ [B] } & Sample & Head milkfish oil (\%) & Palm oil (\%) \\
\hline & 1 & 100 & 0 \\
\hline & 2 & 95 & 5 \\
\hline & 3 & 90 & 10 \\
\hline & 4 & 85 & 15 \\
\hline & 5 & 80 & 20 \\
\hline & 6 & 75 & 25 \\
\hline & 7 & 70 & 30 \\
\hline & 8 & 65 & 35 \\
\hline & 9 & 60 & 40 \\
\hline & 10 & 55 & 45 \\
\hline & 11 & 50 & 50 \\
\hline & 12 & 45 & 55 \\
\hline & 13 & 40 & 60 \\
\hline & 14 & 35 & 65 \\
\hline & 15 & 30 & 70 \\
\hline & 16 & 25 & 75 \\
\hline & 17 & 20 & 80 \\
\hline & 18 & 15 & 85 \\
\hline & 19 & 10 & 90 \\
\hline & 20 & 0 & 100 \\
\hline
\end{tabular}




\subsection{FTIR spectroscopy measurement}

All samples used for quantitative analysis of adulteration and discrimination purpose were analyzed using FTIR spectrophotometer (Thermo Scientific Nicolet iS10, Madison WI) processed using Omnic software. The measurements were carried out in an infrared region of $4000-650 \mathrm{~cm}^{-1}$ using 32 scannings and resolution of $8 \mathrm{~cm}^{-1}$ using attenuated total reflectance composed of ZnSe crystal (Irnawati et al., 2019b; Putri et al., 2019). Before the measurement of each sample, a background spectrum of air was measured using the same condition as that of the sample. All samples were measured in three replicates. During the analysis of samples, ATR crystal was cleaned with $n$-hexane and acetone after FTIR spectral measurement.

\subsection{Chemometrics analysis}

Chemometrics analysis for multivariate calibration and discriminant analysis was performed using the software of TQ analyst 9.7.0.27 (Thermo Fisher Scientific Inc.). Partial least-square (PLS) and principal component regression (PCR) were compared to provide the optimum prediction models for the correlation between actual values and predicted values. Some statistical parameters namely the coefficient of determination $\left(\mathrm{R}^{2}\right)$, root mean square error of calibration (RMSEC) and root mean square error of cross prediction (RMSEP) were calculated using the software. The chemometrics of principal component analysis was carried out using Minitab version 19 (Minitab Inc., USA).

\section{Results and discussion}

The adulteration practice of high priced-oil such as milkfish oil (MFO) with lower-priced oils such as palm oil (PO) having similar colour, aromatic and taste with the original oils can be a serious problem. Therefore, it would be difficult to detect the adulterant and original oil (Christy et al., 2004). Palm oil (PO) is selected to be an oil adulterant in milkfish MFO based on close similarity in FTIR spectra as indicated by principal component analysis (PCA) results. PCA was used to look for oils having similar characteristics with MFO. The principle of PCA is a data reduction technique, and the output was called principle components or score plot. In this study, the absorbances at the whole mid-infrared region (4000$650 \mathrm{~cm}^{-1}$ ) were used to get much information extracted from FTIR spectra (Man et al., 2011). Based on the score plot in the first principle component (PC1) and second principle (PC2), as shown in Figure 1, palm oil, olive oil, pork fat, and candlenut oil had similar values (PC1 and PC2) to flesh and head milkfish. Finally, PO was selected as an adulterant based on similarity with MFO from PCA and the fact that in Indonesia, PO had a lower price than olive oil, pork fat, and candlenut oil. Fish oil obtained from the flesh and the head has a physical similarity based on the score plot except for fish oil from the flesh has a higher yield $(30,4 \%)$ than fish oil from the head (25.04\%).

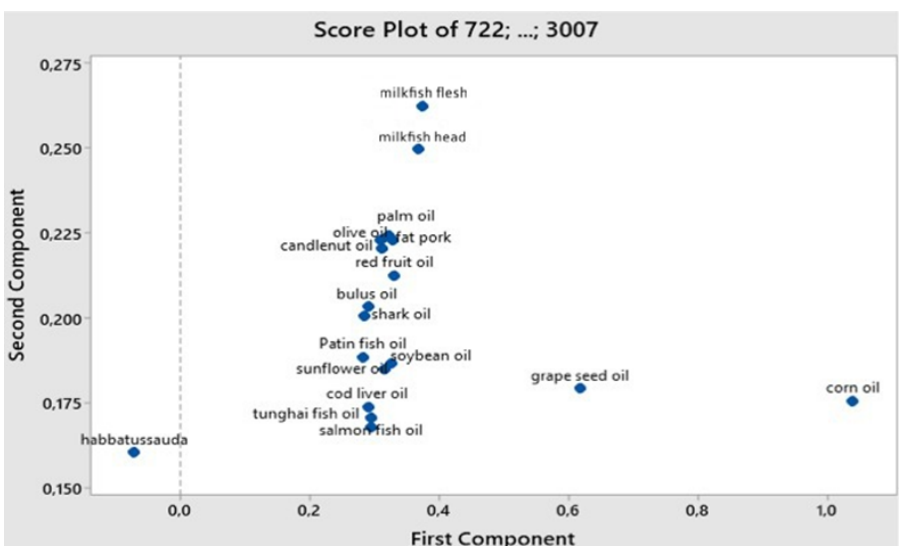

Figure 1. Principal component analysis of milkfish fish oil (MFO)

Figure 1 shows that each wavenumber corresponded with functional groups present in MFO and PO. Peaks at $3007 \mathrm{~cm}^{-1}$ was coming from [cis $=\mathrm{C}-\mathrm{H}$ (stretching)], $2953 \mathrm{~cm}^{-1}\left[-\mathrm{CH}_{3}\right.$, asymmetric stretching], $2922 \mathrm{~cm}^{-1}$ [$\mathrm{CH}_{2}$, asymmetric stretching], $2852 \mathrm{~cm}^{-1} \quad\left[-\mathrm{CH}_{2}\right.$, symmetric stretching], $1744 \mathrm{~cm}^{-1} \quad[-\mathrm{C}=\mathrm{O} \quad$ (ester), stretching], $1652 \mathrm{~cm}^{-1}$ [cis $-\mathrm{C}=\mathrm{C}$, stretching], $1463 \mathrm{~cm}^{-1}$ [- $\mathrm{CH}_{2}$, bending], $1377 \mathrm{~cm}^{-1}\left[-\mathrm{CH}_{3}\right.$, bending], 1238, 1117, 1163, 1098, $1031 \mathrm{~cm}^{-1}$ [-C-O, Stretching], $966 \mathrm{~cm}^{-1}$ [trans $\mathrm{HC}=\mathrm{CH}$ - Out of plane], $913 \mathrm{~cm}^{-1}[-$ cis $\mathrm{HC}=\mathrm{CH}$-out of plane], and peak at $722 \mathrm{~cm}^{-1}$ corresponded to $\left[\left(-\mathrm{CH}_{2}\right)_{\mathrm{n}}\right.$; cis $-\mathrm{HC}=\mathrm{CH}-]$ (Man et al., 2011).

Authentication analysis of MFO mixed with PO analyzed with FTIR spectroscopy combined with two multivariate calibrations of partial least square regression (PLSR) and principle component regression (PCR). The principle of the PLSR method was using the correlation between spectral absorption changes and concentration of samples. PCR method combines spectral and data concentration sample into a model in one step (Putri et al., 2019). For quantification, as in Table 1 [A], 25 samples containing Flesh MFO was mixed with PO with a range concentration of $0-100 \%$. The optimization results of PLS and PCR using variables of absorbance values at several wavenumber regions for modelling the correlation between actual values of MFO and predicted values were compiled 2 along with statistical parameters. The values of $\mathrm{R}^{2}$ and errors (root mean square error of calibration and root mean square error of prediction) indicate the accuracy and precision of FTIR spectroscopy to analyze MFO (Miller and Miller, 2005). Quantitative analysis of MFO with PO was performed with two multivariate calibrations, namely PLS (Partial Least Square) and PCR (Principle Component Analysis). 
Both two multivariate (PLS and PCR) are inverse regression in which concentrations ( $y$-axis) was modelled with predictors of principle components, a linear combination of absorbance values (x-axis) (Irnawati et al., 2019b).

Table 2 shows that PLSR which flesh milkfish fish oil using normal spectrum exploiting absorbance values at a wavenumber of $3200-670 \mathrm{~cm}^{-1}$ have the best values in terms of high $\mathrm{R}^{2}$ and low RMSEC and RMSEP values. The $\mathrm{R}^{2}$ values for the correlation between actual and predicted values in calibration and prediction samples were 0.9997 and 0.9992, while values of RMSEC and RMSEP were $0.0080 \%$ and $0.0123 \%$ respectively as shown in Figure 2. Furthermore, Table 3 shows PLSR which head milkfish oil using first derivate spectra at wavenumber $3100-670 \mathrm{~cm}^{-1}$ have the highest value of $\mathrm{R}^{2}$ and lowest value of RMSEC and RMSEP. The $\mathrm{R}^{2}$ values for the correlation between actual and predicted values in calibration and prediction samples were 0.9999 and 0.9994, while values of RMSEC and RMSEP were
$0.0032 \%$ and $0.0106 \%$ respectively as shown in Figure 3. The aims for the first and the second derivate to increase the separation of the overlapping peaks in normal spectra so that it's expected to increase the molecular specificity of FTIR. Somehow first and second derivative does not give a better result than the normal spectra. Figure 2 and 3 reveals the correlation between actual values (x-axis) of MFO and the predicted values of MFO using FTIR. The figures indicated that the systematic errors did not exist and the model developed are reliable to predict MFO adulterated with PO. The different range concentration between flesh fish oil and head fish oil also has no impact on the analysis results. It can be concluded that the developed method using FTIR combined chemometrics is an accurate and precise tool for the prediction of MFO in binary mixtures with PO.

Discriminant analysis (DA) is one of the supervised pattern recognition technique commonly used for classifying original/authentic samples with oil adulterant (Rohman et al., 2014). Figure 4 reveals the Coomans

Table 2. The optimization of multivariate calibrations of partial least square regression (PLSR) and principle component regression (PCR) as well as wavenumbers region for authentication of Flesh Milkfish Fish Oil (FMFO) with palm oil

\begin{tabular}{|c|c|c|c|c|c|c|}
\hline \multirow{2}{*}{$\begin{array}{l}\text { Multivariate } \\
\text { Calibration }\end{array}$} & \multirow{2}{*}{ Wavenumber $\left(\mathrm{cm}^{-1}\right)$} & \multirow{2}{*}{ Spectra } & \multicolumn{2}{|c|}{ Calibration } & \multicolumn{2}{|c|}{ Validation } \\
\hline & & & $\mathrm{R}^{2}$ & RMSEC & $\mathrm{R}^{2}$ & RMSEP \\
\hline \multirow{15}{*}{ PLS } & \multirow{3}{*}{$3100-670$} & *Normal & 0.9997 & 0.0080 & 0.9992 & 0.0123 \\
\hline & & 1 st der & 0.9997 & 0.0078 & 0.9992 & 0.0127 \\
\hline & & 2 st der & 0.9999 & 0.0038 & 0.9984 & 0.0173 \\
\hline & \multirow{3}{*}{$1800-670$} & Normal & 0.9997 & 0.0071 & 0.9990 & 0.0146 \\
\hline & & 1 st der & 0.9994 & 0.0103 & 0.9986 & 0.0170 \\
\hline & & 2st der & 0.9990 & 0.0138 & 0.9973 & 0.0229 \\
\hline & \multirow{3}{*}{$\begin{array}{c}3050-2800 \text { and } \\
1800-670\end{array}$} & Normal & 0.9996 & 0.0091 & 0.9994 & 0.0103 \\
\hline & & 1 st der & 0.9994 & 0.0106 & 0.9992 & 0.0124 \\
\hline & & 2 st der & 0.9993 & 0.0116 & 0.9988 & 0.0154 \\
\hline & \multirow{3}{*}{$\begin{array}{c}3050-2800 \text { and } \\
1500-1000\end{array}$} & Normal & 0.9992 & 0.0124 & 0.9995 & 0.0108 \\
\hline & & 1 st der & 0.9997 & 0.0071 & 0.9994 & 0.0108 \\
\hline & & 2 st der & 0.9999 & 0.0040 & 0.9986 & 0.0164 \\
\hline & \multirow{3}{*}{$\begin{array}{l}800-670 \text { and } 1800- \\
1000\end{array}$} & Normal & 0.9997 & 0.0070 & 0.9990 & 0.0148 \\
\hline & & 1 st der & 0.9994 & 0.0108 & 0.9985 & 0.0017 \\
\hline & & 2 st der & 0.9989 & 0.0146 & 0.9976 & 0.0217 \\
\hline \multirow{15}{*}{ PCR } & \multirow{3}{*}{$3100-670$} & Normal & 0.9996 & 0.0085 & 0.9993 & 0.0115 \\
\hline & & 1 st der & 0.9994 & 0.0109 & 0.9992 & 0.0124 \\
\hline & & 2 st der & 0.9988 & 0.0149 & 0.9983 & 0.0181 \\
\hline & \multirow{3}{*}{$1800-670$} & Normal & 0.9995 & 0.0096 & 0.9992 & 0.0131 \\
\hline & & 1 st der & 0.9993 & 0.0118 & 0.9988 & 0.0152 \\
\hline & & 2 st der & 0.9984 & 0.0176 & 0.9970 & 0.0243 \\
\hline & \multirow{3}{*}{$\begin{array}{c}3050-2800 \text { and } \\
1800-670\end{array}$} & Normal & 0.9995 & 0.0094 & 0.9993 & 0.0112 \\
\hline & & 1 st der & 0.9994 & 0.0109 & 0.9993 & 0.0115 \\
\hline & & 2 st der & 0.9990 & 0.0136 & 0.9986 & 0.0164 \\
\hline & \multirow{3}{*}{$\begin{array}{c}3050-2800 \text { and } \\
1500-1000\end{array}$} & Normal & 0.9994 & 0.0105 & 0.9995 & 0.0097 \\
\hline & & 1 st der & 0.9994 & 0.0103 & 0.9994 & 0.0108 \\
\hline & & 2 st der & 0.9993 & 0.0112 & 0.9988 & 0.0155 \\
\hline & \multirow{3}{*}{$\begin{array}{l}800-670 \text { and } 1800- \\
1000\end{array}$} & Normal & 0.9995 & 0.0098 & 0.9992 & 0.0133 \\
\hline & & 1 st der & 0.9993 & 0.0119 & 0.9988 & 0.0153 \\
\hline & & 2 st der & 0.9983 & 0.0181 & 0.9975 & 0.0220 \\
\hline
\end{tabular}

*The selection condition was assigned in bold. 1 st der $=$ first derivative spectra; 2 nd der $=$ second derivative spectra. 
Table 3. The optimization of multivariate calibrations of partial least square regression (PLSR) and principle component regression (PCR) as well as wavenumbers region for authentication of Head Milkfish Fish Oil (HMFO) with palm oil

\begin{tabular}{|c|c|c|c|c|c|c|}
\hline \multirow{2}{*}{$\begin{array}{c}\text { Multivariate } \\
\text { Calibration }\end{array}$} & \multirow{2}{*}{ Wavenumber $\left(\mathrm{cm}^{-1}\right)$} & \multirow{2}{*}{ Spectra } & \multicolumn{2}{|c|}{ Calibration } & \multicolumn{2}{|c|}{ Validation } \\
\hline & & & $\mathrm{R}^{2}$ & RMSEC & $\mathrm{R}^{2}$ & RMSEP \\
\hline \multirow{15}{*}{ PLS } & \multirow{3}{*}{$3100-670$} & Normal & 0.9972 & 0.0219 & 0.9957 & 0.0272 \\
\hline & & $* 1$ st der & 0.9999 & 0.0032 & 0.9994 & 0.0106 \\
\hline & & 2 st der & 0.9983 & 0.0171 & 0.9975 & 0.0207 \\
\hline & \multirow{3}{*}{$2000-670$} & Normal & 0.9997 & 0.0073 & 0.9991 & 0.0121 \\
\hline & & 1 st der & 0.9995 & 0.0096 & 0.999 & 0.0128 \\
\hline & & 2 st der & 0.9952 & 0.0286 & 0.9901 & 0.0411 \\
\hline & \multirow{3}{*}{$\begin{array}{c}3100-2700 \text { and } \\
2000-670\end{array}$} & Normal & 0.9997 & 0.0066 & 0.9996 & 0.0078 \\
\hline & & 1 st der & 0.999 & 0.0131 & 0.999 & 0.0129 \\
\hline & & 2 st der & 0.9983 & 0.0172 & 0.9977 & 0.0201 \\
\hline & \multirow{3}{*}{$\begin{array}{c}3100-2700 \text { and } \\
1850-1650\end{array}$} & Normal & 0.9983 & 0.0172 & 0.998 & 0.0187 \\
\hline & & 1 st der & 0.9989 & 0.0135 & 0.9991 & 0.0124 \\
\hline & & 2 st der & 0.9997 & 0.0072 & 0.9988 & 0.0142 \\
\hline & \multirow{3}{*}{$\begin{array}{c}3050-2750 \text { and } \\
1500-670\end{array}$} & Normal & 0.9995 & 0.0096 & 0.9995 & 0.0093 \\
\hline & & 1 st der & 0.999 & 0.0132 & 0.999 & 0.0132 \\
\hline & & 2 st der & 0.9985 & 0.0161 & 0.9981 & 0.0184 \\
\hline \multirow{15}{*}{ PCR } & \multirow{3}{*}{$3100-670$} & Normal & 0.9997 & 0.008 & 0.9997 & 0.0078 \\
\hline & & 1st der & 0.9998 & 0.0064 & 0.9993 & 0.0108 \\
\hline & & 2 st der & 0.9995 & 0.0093 & 0.9984 & 0.0176 \\
\hline & \multirow{3}{*}{$2000-670$} & Normal & 0.9997 & 0.0074 & 0.999 & 0.0131 \\
\hline & & 1 st der & 0.9996 & 0.0083 & 0.9991 & 0.0122 \\
\hline & & 2 st der & 0.9983 & 0.0168 & 0.9957 & 0.028 \\
\hline & $3100-2700$ & Normal & 0.9997 & 0.0069 & 0.9996 & 0.0083 \\
\hline & \multirow[t]{2}{*}{$2000-670$} & 1 st der & 0.9997 & 0.0069 & 0.9994 & 0.0099 \\
\hline & & 2 st der & 0.9995 & 0.0091 & 0.9986 & 0.016 \\
\hline & $3100-2700$ & Normal & 0.9997 & 0.0077 & 0.9996 & 0.0083 \\
\hline & \multirow[t]{2}{*}{$1850-1650$} & 1 st der & 0.9997 & 0.0077 & 0.9992 & 0.0120 \\
\hline & & 2 st der & 0.9994 & 0.0099 & 0.9988 & 0.0143 \\
\hline & $3050-2750$ & Normal & 0.9997 & 0.0068 & 0.9997 & 0.0075 \\
\hline & \multirow[t]{2}{*}{$1500-670$} & 1 st der & 0.9997 & 0.0071 & 0.9993 & 0.011 \\
\hline & & 2 st der & 0.9993 & 0.0106 & 0.9983 & 0.0179 \\
\hline
\end{tabular}

*The selection condition was assigned in bold. 1 st der $=$ first derivative spectra; 2 nd der $=$ second derivative spectra.

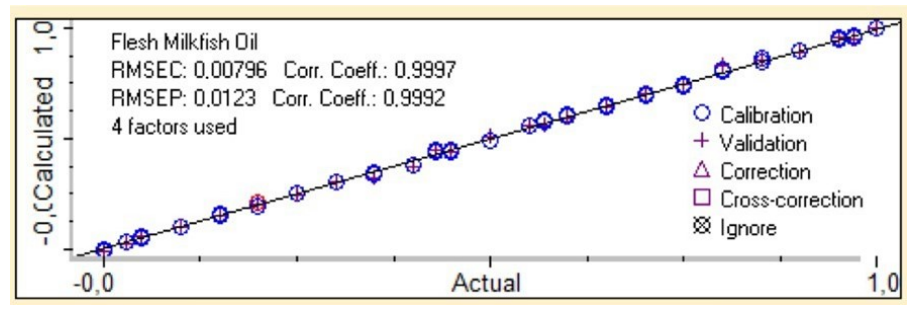

[A]

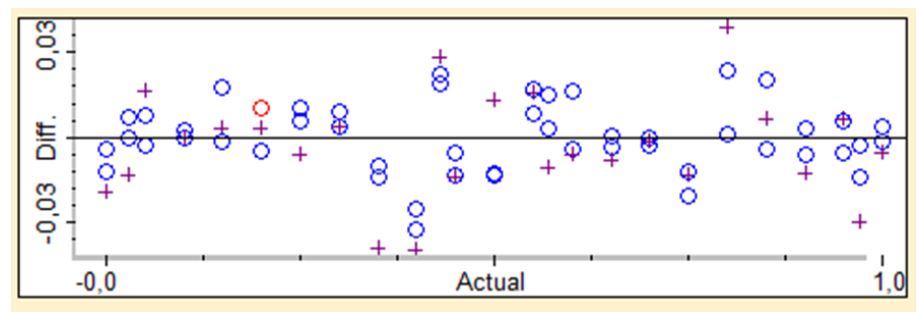

[B]

Figure 2. The correlation between actual and predicted values of flesh fish oil in calibration and prediction samples [A] along with residual analysis [B]

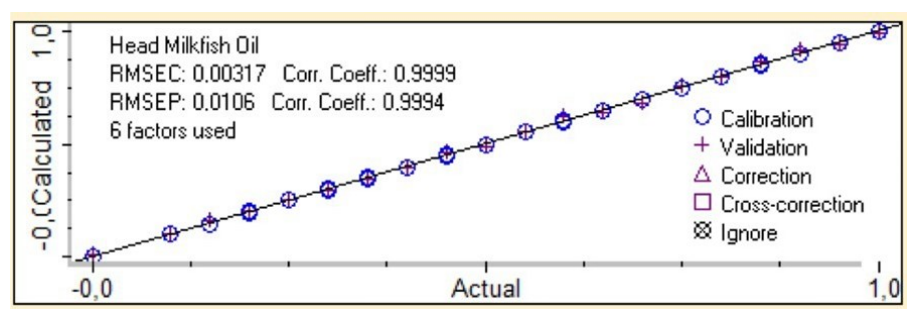

[A]

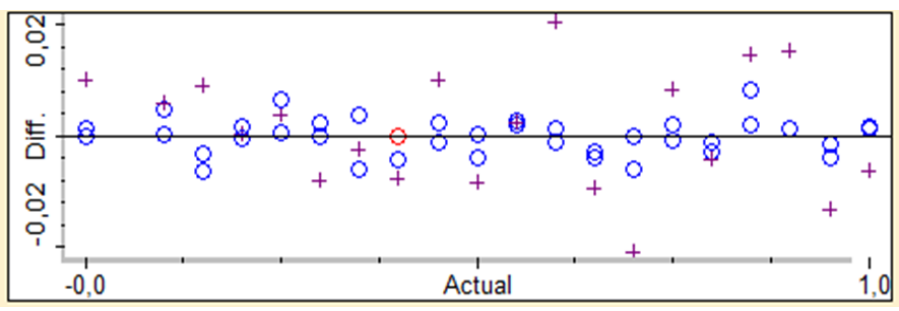

[B]

Figure 3. The correlation between actual and predicted values of head fish oil in calibration and prediction samples [A] along with residual analysis [B] 

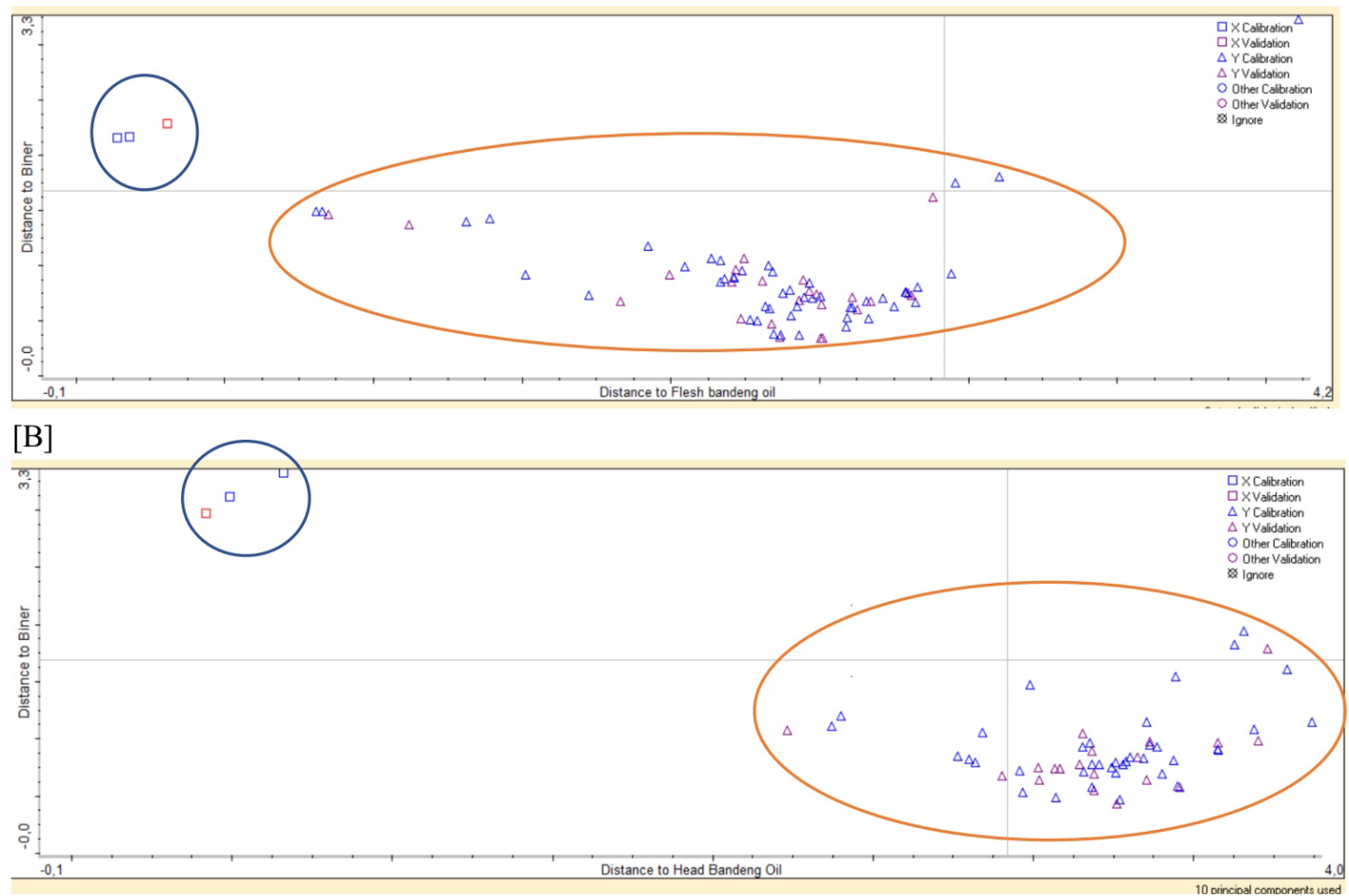

Figure 4. The Cooman plot for discrimination between milkfish fish oil (MFO) [-] and MFO adulterated with palm oil [ $\mathbf{\Delta}]$ : [A] Flesh Milkfish Fish oil, [B] Head Milkfish fish oil

plot of DA for classification of MFO extracted from flesh [A] and head [B] and MFO adulterated with PO. The $-x$ axis indicates Mahalanobis distance to pure "MFO", while the $-y$ axis shows the distance Mahalanobis of "MFO mixed with PO". The Mahalanobis distances useful to determine the similarity or dissimilarity of a series of unknown samples against a series known sample as a pure sample (Rohman and Man, 2012). The discriminant analysis method is capable of grouping the oils with an accuracy level of $100 \%$ using absorbance values at whole wavenumber regions 4000-650 $\mathrm{cm}^{-1}$ and Mahalanobis distances (Irnawati et al., 2019a). This result indicated that DA as an effective tool to classify pure MFO from potential adulterants such as palm oil.

\section{Conclusion}

Fourier transform infrared (FTIR) spectroscopy in combination with chemometrics of partial least square (PLS) regression and discriminant analysis was successfully used for quantification and classification of MFO adulterated with PO. FTIR spectra at wavenumbers of 3100-670 $\mathrm{cm}^{-1}$ coupled with PLSR was successfully applied for quantification with acceptable precision and accuracy. Discriminant analysis using absorbance values at the whole mid-infrared region also could classify MFO and that adulterated with PO without any misclassified observed. The developed method is rapid and eases operation without involving excessive sample preparation.

\section{Conflict of interest}

The authors declare no conflict of interest.

\section{Acknowledgements}

The authors thank the Ministry of Research and technology Republic of Indonesia.

\section{References}

Ali, S.S.R. (2017). Effect of Varying Levels of Lipid on Growth Performance, Survival and Body Composition of Milkfish (Chanos chanos). International Journal of Fisheries and Aquatic Studies, 5(4), 30-34.

Bayaga, C. and Devega, G. (2005). Milkfish (Chanos chanos Forskaal) Consumption in the Philippines and the Docosahexaenoic Acid Level of the Cooked Fish. Food Science and Technology Research, 11(1), 127-133. https://doi.org/10.3136/fstr.11.127

Christy, A.A., Kasemsumran, S., Du, Y. and Ozaki, Y. (2004). The Detection and Quantification of Adulteration in Olive Oil by Near-Infrared Spectroscopy and Chemometrics. Analytical Sciences, 20(6), 935-940. https://doi.org/10.2116/ analsci.20.935

Durmuş, M. (2019). Fish Oil for Human Health: Omega3 Fatty Acid Profiles of Marine Seafood Species. Food Science and Technology Research, 39, 454 461. https://doi.org/10.1590/fst.21318 
Gezahegn, T.L. (2018). Fourier Transform Infrared Spectroscopy Combined with Partial Least Squared Regression and Standard Addition-Net Analyte Signal Method for Quantification of Chitin in Insectbased Fish Feeds. Norway: University of Bergen, MSc. Thesis.

Irnawati, I., Riyanto, S., Martono, S. and Rohman, A. (2019a). The Employment of FTIR Spectroscopy and Chemometrics for Authentication of Pumpkin Seed Oil from Sesame Oil. Food Research, 4(1), 4248. https://doi.org/10.26656/fr.2017.4(1).198

Irnawati, I., Riyanto, S., Martono, S. and Rohman, A. (2019b). Determination of sesame oil, rice bran oil and pumpkin seed oil in ternary mixtures using FTIR spectroscopy and multivariate calibrations. Food Research, 4(1), 135-142. https://doi.org/10.26656/ fr.2017.4(1).260

Man, Y.B.C., Rohman, A. and Mansor, T.S.T. (2011). Differentiation of Lard From Other Edible Fats and Oils by Means of Fourier Transform Infrared Spectroscopy and Chemometrics. Journal of the American Oil Chemists' Society, 88(2), 187-192. https://doi.org/10.1007/S11746-010-1659-X

Miller, J.N. and Miller, J.C. (2005). Statistics and Chemometrics for Analytical Chemistry, 5th ed. New York: Pearson Prentice Hall.

Murthy, L.N., Padiyar, P., Rao, M., K.K., A., Jesmi, D., Phadke, G., Prasad, M. and Ravishankar, C. (2016). Nutritional Profile and Heavy Metal Content of Cultured Milkfish (Chanos chanos). FISH Technology, 53, 245-249.

Putri, A.R., Rohman, A. and Riyanto, S. (2019). Authentication of Patin (Pangasius Micronemus) Fish Oil Adulterated with Palm Oil using FTIR Spectroscopy combined with Chemometrics. International Journal of Applied Pharmaceutics, 11 (3), 195-199. https://doi.org/10.22159/ ijap.2019v11i3.30947

Rohman, A. (2017). Infrared spectroscopy for quantitative analysis and oil parameters of olive oil and virgin coconut oil: A review. International Journal of Food Properties, 20(7), 1447-1456. https://doi.org/10.1080/10942912.2016.1213742

Rohman, A., Che Man, Y.B. and Ali, M.E. (2019). The Authentication of Virgin Coconut Oil from Grape Seed Oil and Soybean Oil using FTIR Spectroscopy and Chemometrics. International Journal of Applied Pharmaceutics, 11(2), 259-263. https:// doi.org/10.22159/ijap.2019v11i2.31758

Rohman, A., Che Man, Y.B. and Yusof, F.M. (2014). The Use of FTIR Spectroscopy and Chemometrics for Rapid Authentication of Extra Virgin Olive Oil.
Journal of the American Oil Chemists' Society, 91 (2), 207-213. https://doi.org/10.1007/s11746-0132370-5

Rohman, A., Irnawati, I., Erwanto, Y., Lukitaningsih, E., Rafi, M., Fadzilah, N., Windarsih, A., Sulaiman, A. and Zakaria, Z. (2019). Virgin Coconut Oil: Extraction, Physicochemical Properties, Biological Activities and Its Authentication Analysis. Food Reviews International, 37(1), 46-66. https:// doi.org/10.1080/87559129.2019.1687515

Rohman, A. and Man, Y.B.C. (2012). Pengembangan Metode Deteksi Minyak Kedelai Dalam Campuran Minyak Kelapa Murni Dengan Spektroskopi Infra Merah dan Kemometrika. AGRITECH, 32, 111-116. [In Bahasa Indonesia].

Rohman, A., Widyanintyas, F. and Amalia, F. (2017). Authentication of CO-liver Oil from Selected Edible Oils using FTIR Spectrophotometry and Chemometrics. International Food Research Journal, 24(4), 1362-1367.

Setyaningrum, D.L., Riyanto, S. and Rohman, A. (2013). Analysis of Corn and Soybean Oils in Red Fruit Oil using FTIR Spectroscopy in Combination with Partial Least Square. International Food Research Journal, 20(4), 1977-1981.

Sugata, M., Wiriadi, F., Lucy, J. and Tan, T.J. (2019). Total lipid and omega-3 content in Pangasius catfish (Pangasius pangasius) and milkfish (Chanos chanos) from Indonesia. Malaysian Journal of Nutrition, 25(1), 163-169. https://doi.org/10.31246/ mjn-2018-0137 